\title{
POLÍTICA EDITORIAL E ESCOPO DA REVES
}

\author{
EDITORIAL POLICY AND SCOPE OF REVES
}

Wagner dos Reis Marques Araújo ${ }^{1}$, Antonio Marcos de Oliveira Siqueira ${ }^{2}$, Aldair Oliveira de Andrade $^{3}$, Roberta Ferreira Coelho de Andrade ${ }^{4}$

1 Universidade do Estado de Minas Gerais, UEMG - Unidade Abaeté, MG Brasil, e-mail: wagner.araujo@uemg.br

${ }^{2}$ Universidade Federal de Viçosa, Viçosa, MG, Brasil, e-mail: antonio.siqueira@ufv.br

${ }^{3}$ Universidade Federal do Amazonas, Programa de Pós-Graduação em Ciências e Humanidades (PPGCH), Brasil, e-mail: aldairandrade@ yahoo.com.br

4 Universidade Federal do Amazonas, Departamento de Serviço Social, Manaus/AM, Brasil, roberta ufam@yahoo.com.br

\section{A R T I C L E I N F O}

Article history:

Received 2019-12-20

Accepted 2019-12-20

Available online 2019-12-20
Palavras-chave: Editoração científica. Periódico. Normas.

Keywords: Scientific publishing. Periodic. Publication standards.

A REVES - Revista Relações Sociais é uma publicação de fluxo contínuo (com 4 números por ano: N. 1 - até final de março; N. 2 - até final de junho; N. 3 - até final de setembro e N. 4 - até final de dezembro), cujo objetivo é publicar trabalhos inéditos sobre temas relevantes das Ciências Sociais, mantendo uma linha interdisciplinar, com contribuições da Sociologia, da Antropologia, da Ciência Política e Filosofia, bem como de áreas afins. Os trabalhos/manuscritos submetidos a revista REVES podem ser enquadrados nos seguintes formatos:

- Editorial.

- Artigos.

- Resenhas.

- Relatos de Experiências.

- Resumos.

\section{TEMPLATE}

A intenção do template é padronizar a formatação dos artigos encaminhados à REVES - Revista Relações Sociais, com vistas a melhorar a qualidade dos trabalhos, buscando a excelência na publicação científica. Assim, tais padrões estão adequados às revistas e aos critérios de indexação da base SciELO (Scientific Electronic Library Online). Este plano de ação tem como objetivos principais: a) Facilitar a correção dos textos; b) Auxiliar o autor no processo de formatação; c) Adequação da periodicidade das publicações aos critérios SciELO; d) Fortalecer o Comitê Editorial da REVES Revista Relações Sociais; e) Padronizar o estilo e layout da revista (diagramação e conteúdo, capa e sumário).

\section{Editorial Team/Estrutura Editorial}




\section{ESTRUTURA EDITORIAL}

A estrutura editorial do periódico é constituída pelo Corpo Editorial, Revisores Ad Hoc e Secretaria do periódico.

1. CORPO EDITORIAL. A COMPOSIÇÃO: Deverá ser constituído por especialistas reconhecidos na comunidade científica da área. O Corpo Editorial será constituído por:

a) Editor-Chefe (Editor-in-Chief).

b) Editor Adjunto (Adjunct Editor)

c) Editor Associado (Associate Editor)

Os nomes dos membros do Corpo Editorial constarão do website do periódico.

ATRIBUIÇÕES GERAIS DO CORPO EDITORIAL:

- Promover a divulgação do periódico.

- Identificar, selecionar e substituir Revisores Ad Hoc;

- Definir a política editorial e a missão do periódico;

- Deliberar sobre a identidade visual e o processo editorial do periódico;

- Zelar pela qualidade técnico-científica do periódico, pela regularidade de sua publicação e pelo processo de gestão editorial;

- Avaliar periodicamente e propor modificações das Normas do periódico, visando manter sua qualidade e atratividade;

- Sugerir autores, resenhas e traduções;

- Sugerir eixos temáticos.

2. REVISORES AD Hoc ATRIBUIÇÕES GERAIS:

- Concordar em rever manuscritos apenas em assuntos nos quais tenha experiência;

- Declarar qualquer conflito de interesse potencial ou real com relação à Revista ou ao trabalho;

- Emitir parecer sobre os manuscritos no processo de avaliação cega para os dois lados - double blind review;

- Realizar a revisão dentro do prazo estabelecido pelo periódico;

- Respeitar a confidencialidade da revisão e não revelar quaisquer detalhes do trabalho;

- Ser objetivo e construtivo nos comentários, evitando críticas pessoais, hostis, difamatórias ou depreciativas;

- Utilizar formulário próprio, fornecido pela Revista, para relatar as considerações sobre o trabalho;

- Obedecer as Diretrizes éticas para revisores de periódicos científicos;

- Indicar novos Revisores.

\section{SECRETARIA}

\section{ATRIBUIÇÕES GERAIS:}

- Recepcionar os trabalhos submetidos à publicação, organizar e gerenciar o fluxo de gestão de manuscritos, pareceres e comunicações com o Corpo Editorial;

- Orientar os autores quanto à adequação dos textos às normas de publicação e outros procedimentos pertinentes ao processo de análise e aprovação dos trabalhos;

- Fazer a revisão inicial dos manuscritos quanto ao atendimento das normas do periódico

- Gerenciar o fluxo de manuscritos no processo editorial para garantir o cumprimento de prazos;

- Gerenciar os processos relativos aos serviços de revisão, edição e deagramação do periódico;

- Manter o registro de avaliações de desempenho de Revisores Ad Hoc;

- Manter atualizado o cadastro de Editores, Conselheiros e Revisores;

- Providenciar a divulgação dos artigos e do periódico;

- Contabilizar gastos e arrecadação relacionados às edições do periódico;

- Controlar os pagamentos efetuados pelos autores;

- Providenciar a indexação da revista junto aos vários sistemas de informação que contemplem a área;

- Manter atualizado o site do periódico. 